\title{
MÉTODOS DE TRANSFORMACIÓN GENÉTICA DE PLANTAS
}

\section{PLANT GENETIC TRANSFORMATION METHODS}

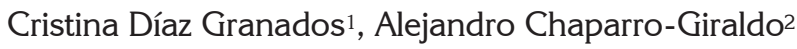

\begin{abstract}
1 Microbióloga Industrial, M.Sc., cPh.D. Grupo de Ingeniería Genética de Plantas, Departamento de Biología \& Instituto de Genética, Universidad Nacional de Colombia. E-mail: ecdiazg@una.edu.co 2 Ingeniero Agrónomo, M.Sc., Ph.D. Grupo de Ingeniería Genética de Plantas, Departamento de Biología \& Instituto de Genética, Universidad Nacional de Colombia, sede Bogotá. E-mail: achaparrog@bt.unal.edu.co
\end{abstract}

Rev. U.D.C.A Act. \& Div. Cient. 15(1): 49 - 61, 2012

\section{RESUMEN}

Con el propósito de hacer más eficiente la transferencia de ADN hacia células vegetales, se han desarrollado diferentes métodos de transformación genética en plantas. Los métodos indirectos son basados en la utilización de vectores biológicos y los métodos indirectos son basados en elementos físicos y químicos. Esta es una revisión actualizada de los métodos de transformación genética de plantas, dirigida a los interesados en el mejoramiento genético de cultivos. Para ello, se revisaron las bases de datos "Science Direct", "Hinari" y "Medline", disponibles en el portal del sistema nacional de bibliotecas (SINAB), de la Universidad Nacional de Colombia. Se usaron las palabras claves en inglés "plant transformation", "genetic engineering", "transgenic plants", "genetically modified crops", para la búsqueda de documentos generales. Posteriormente, se refinó la búsqueda con el uso de palabras claves específicas, como "particle bombardment", "biolistic", "Agrobacterium", "sonication" y otras. También, se realizaron algunas pesquisas de complementación en idioma español, usando el buscador "google", para las palabras claves "cultivos genéticamente modificados" y "cultivos transgénicos". Se examinaron artículos científicos y revisiones publicadas, entre 1997 y 2010. Existe una larga lista de procesos usados en la transferencia de genes foráneos a los genomas de especies vegetales, que incluye: vectores virales, liposomas, electroporación, sonicación, transferencia mediada por compuestos químicos, fibras de carburo de silicona, microinyección y microlaser; sin embargo, los cultivos transgénicos que se han liberado comercialmente, se han producido mediante el uso de dos tecnologías: biobalística y transformación, mediada por Agrobacterium tumefaciens.

Palabras clave: Plantas transgénicas, cultivos genéticamente modificados, transformación genética.

\section{SUMMARY}

In order to streamline the transfer of DNA into plant cells have developed different methods for genetic transformation in plants. These methods can be divided into two classes: indirect methods based on biological vectors known as, and direct methods based on physical and chemical elements. This work presents an updated review of the methods used for genetic transformation of plants, aimed at those interested in crops breeding. To do this we reviewed databases "Science Direct", "Hinari" and "Medline" available on the website of the national library system (SINAB) of the Universidad Nacional de Colombia. Keywords used in English were: "plant transformation", "genetic engineering", "transgenic plants", "genetically modified crops", to search for general documents. Search was further refined by using more specific keywords, like "particle bombardment", "biolistic", "Agrobacterium", "sonication", etc. Also conducted some research complementation in Spanish, using the search "google" for the key words "cultivos genéticamente modificados" and " cultivos transgénicos". Were reviewed scientific articles and reviews between 1997 and 2010. There is a long list of processes used in the transfer of foreign genes into the genomes of plant species, including: viral vectors, liposomes, electroporation, sonication, chemical-mediated transfer, silicon carbide fibers, microinjection and microlaser. However, GM crops are released commercially, have been produced through the use of two technologies: biolistic and Agrobacterium tumefaciens-mediated transformation.

Key words: Transgenic plants, GM crops, genetic transformation.

\section{INTRODUCCIÓN}

La ingeniería genética de plantas está dirigida a la produc- 
ción de genotipos que expresen características de interés, mediante la integración en el genoma vegetal, de segmentos de DNA foráneo, proveniente de cualquier origen. Este DNA altera las características de la planta, mediante la modificación dirigida y controlada de su genoma, al añadir, al eliminar o al modificar alguno o algunos de sus genes (Danilova, 2007; Karimi et al. 2007). No hay limitación para la transferencia de genes entre plantas de la misma especie y especies cercanamente emparentadas, ya que genes de especies no relacionadas evolutivamente, pueden ser introducidos. Ello permite usar genes de diferentes especies, géneros y reinos, eliminando las barreras de incompatibilidad sexual y fertilidad (Vasil, 2007).

La principal ventaja de la ingeniería genética es que no implica la transferencia de cientos de miles de genes, algunos con características no deseadas, sino que involucra el traspaso de uno o pocos genes que confieren la característica de interés (Danilova, 2007). Es un instrumento valioso que permite acelerar procesos que, lentos y laboriosos, ofrece la posibilidad de introducir en una planta una característica deseada, mediante transformación genética, en un solo paso. La ingeniería genética de plantas comprende una serie de técnicas complementarias con los procedimientos del mejoramiento genético convencional (Jauhar, 2006; Livermore, 2002).

La transformación de plantas usa una amplia gama de herramientas, mediante, las cuales, es posible la introducción de información genética foránea, sin afectar las cualidades agronómicas y de mercadeo de los cultivos. La transformación de plantas se ha definido como la incorporación estable de genes foráneos y la expresión de estos en las plantas transformadas (Sharma et al. 2002; Rommens, 2004).

Desde 1983, cuando se reportó por primera vez la producción de una planta transgénica, se ha logrado la transformación de más de 120 especies y 35 diferentes familias vegetales, tanto de dicotiledóneas como de monocotiledóneas (Bhat \& Srinivasan, 2002; Jauhar, 2006). Esto no significa que sea un proceso sencillo, por lo contrario, es un proceso complicado que involucra varias etapas: identificación y aislamiento del gen de interés, desarrollo del casete de expresión o construcción quimérica, vectores apropiados que permitan el clonaje o transferencia de la construcción quimérica, método para la introducción del DNA de manera estable en el genoma de la célula vegetal (protocolo de transformación), sistema de cultivo de tejidos que permita regenerar plantas completas, procedimiento para la distinción de los individuos transformados de aquellos no transgénicos (selección de transformantes) y métodos analíticos para detectar el gene foráneo y sus productos en la planta transformada (Díaz et al. 2004; Larik et al. 2004; Jauhar, 2006).
Según Díaz et al. (2004), para obtener una planta transgénica deben ocurrir tres procesos indispensables en la misma célula: el casete de expresión debe ser transferido al interior de la célula; el casete de expresión se debe integrar al DNA celular y se debe regenerar una planta, a partir de la célula en la que han ocurrido los dos procesos anteriores.

Para todas las técnicas de transformación vegetal es necesario disponer de un gen de interés, que puede ser endógeno modificado o un gen foráneo aislado de grupos filogenéticos variados (Karimi et al. 2007). Este debe ir flanqueado por los elementos reguladores necesarios para su expresión: una región promotora, cuya función general es el reconocimiento del sitio de unión de la DNA polimerasa con el consecuente inicio de la transcripción del gen en RNA mensajero y una región terminadora que da la señal de finalización de la transcripción, y es la encargada del mantenimiento de la estabilidad del mRNA y su transporte al citoplasma para su posterior traducción en una molécula proteica. Esta construcción Región promotora - Región codificante o gen de interés - Región terminadora, es conocida como casete de expresión (Sharma et al. 2002; Chaparro et al. 2005).

La fuente de los segmentos génicos que componen el casete de expresión puede corresponder a orígenes biológicos diferentes, caso en que se denomina construcción quimérica. Este casete de expresión debe ir en un vector que permita su clonación o transferencia, mediante los métodos de transformación. Los vectores más utilizados en la transformación de plantas son plásmidos, donde fueron clonados los genes que serán introducidos en el genoma vegetal (Larik et al. 2004; Job, 2002; Karimi et al. 2007). La construcción quimérica, usualmente, se encuentra acompañada con otra construcción funcional, que corresponde a un gen marcador de selección. La introducción de este gen responde a la necesidad de identificar las plántulas que hayan sido regeneradas, a partir de células que insertaron el transgen dentro del conjunto del material vegetal sometido al proceso de transformación (Bhat \& Srinivasan, 2002; Martínez et al. 2004; Karimi et al. 2007).

Los métodos de transformación utilizados, en la actualidad, se basan en la obtención de células transgénicas y posterior recuperación de plantas completas y fértiles, a través del cultivo de tejidos y selección in vitro. En la mayoría de especies, se observa una importante influencia del genotipo en la respuesta al cultivo in vitro. Por ello, cuando se usa esta tecnología, con fines de mejoramiento genético es muy importante conocer la respuesta morfogenética de los distintos genotipos (Eapen, 2008; Gutiérrez et al. 2002; Filipecki \& Malepszy, 2006). Una vez se logra la regeneración de las plantas transgénicas a partir de células transformadas, se debe realizar la verificación del estatus transgénico de estas plantas, mediante el uso de técnicas moleculares, 
como PCR o "Southern blot", para determinar la inserción del transgen, RT-PCR o "Northern blot", para verificar su transcripción y "Western Blot" o ELISA, para detectar la producción de la proteína (Díaz et al. 2004; Danilova, 2007).

Se denominan plantas transgénicas a aquellas plantas que fueron modificadas genéticamente por la introducción de uno o varios genes (con sus respectivas secuencias reguladoras), por técnicas moleculares, que les confieren una(s) nueva(s) característica (Martínez et al. 2004; Vain, 2007). Las plantas transgénicas fueron desarrolladas por primera vez a comienzos de los 80, por cuatro grupos que trabajaban de manera independiente. Se produjeron células de plantas de tabaco y plantas de petunia resistentes a kanamicina; también, por primera vez, se insertó un gen del fríjol en una planta de girasol (Birch, 1997; Nielsen et al. 2001; Vasil, 2007).

La obtención de plantas transgénicas ha permitido desarrollar nuevas variedades de plantas, cultivadas con características de interés, como son resistencia a factores bióticos y abióticos, aumento en la calidad y rendimientos más altos. También, se ha demostrado la utilidad de las plantas transgénicas para producir vacunas u otras sustancias terapéuticas y para la producción de materias primas de interés industrial, como plásticos biodegradables. De acuerdo a lo anterior es claro el alto potencial y la amplia aplicabilidad de las plantas transgénicas, no solo en la agricultura sino en la industria en general (Job, 2002; Sharma et al. 2002; Vain, 2007).

La disponibilidad de esta tecnología permitió importantes avances en el mejoramiento genético de plantas. El gran esfuerzo realizado, en este sentido, tuvo como consecuencia la llegada al mercado, a partir de 1995, de los primeros cultivos transgénicos (James, 2005; 2008; Vain, 2007). En el 2010, se sembraron 148 millones de hectáreas de cultivos GM, por 15,4 millones de agricultores, en 29 países (James, 2010). Según Agrobio (2011), para el 2010, se sembraron en cultivos transgénicos en Colombia, 37.657ha del algodonero, 38.896ha de maíz y 4ha de clavel y de rosas.

El presente trabajo tiene como propósito ofrecer una visión actualizada de los diferentes métodos usados para la transferencia de genes hacia los genomas de especies vegetales, para los especialistas y los interesados en el mejoramiento genético de plantas. No existe este tipo de documentos en idioma español y esto dificulta la comprensión de esta importante aplicación de la biotecnología vegetal, asunto de interés para países megadiversos, como Colombia, en el que se utilizan los cultivos transgénicos en la agricultura.

\section{MATERIALES Y MÉTODOS}

Se hizo una búsqueda inicial, procurando revisiones generales, usando las bases de datos "Science Direct", "Hinari" y "Medline", disponibles en el portal del sistema nacional de bibliotecas (SINAB), de la Universidad Nacional de Colombia. Para esta primera fase, se emplearon las palabras claves en idioma inglés "plant transformation", "genetic engineering", "transgenic plants", "genetically modified crops". Con base en los hallazgos de la primera fase, se organizó una segunda fase, refinando la pesquisa, de acuerdo con palabras clave relacionadas con los métodos específicos: "particle bombardment", "biolistic", "Agrobacterium", "sonication", "viral vectors", "electroporation", "microlaser", "microinyection", "chemical-mediated transfer", "silicon carbide fibers", "liposomes". Finalmente, se hicieron algunas indagaciones complementarias en idioma español, usando el buscador google, para las palabras claves "cultivos genéticamente modificados" y "cultivos transgénicos". Se examinaron artículos científicos y revisiones entre 1997 y 2010, que cubrieron las publicaciones mundiales en revistas indexadas y páginas web de organizaciones reconocidas, por su dedicación al tema de los cultivos transgénicos, como Agrobio (Asociación de Biotecnología Vegetal Agrícola) e ISAAA (International Service for the Acquisition of Agribiotech Applications).

\section{RESULTADOS Y DISCUSIÓN}

Se han desarrollado diferentes métodos de transformación genética, con el propósito de hacer más eficiente la transferencia de ADN hacia células o tejidos vegetales. Se busca transformar una variedad más amplia de plantas con mejores resultados. Los sistemas de transformación con los que se cuenta en la actualidad, se clasifican en métodos indirectos y métodos directos, de acuerdo con el mecanismo utilizado para la transferencia del material genético hacia la célula vegetal (Mohan Babua et al. 2003; Rao et al. 2009). La cisgenesis que es la introducción de genes con sus promotores nativos aislados desde la planta cultivada en sí misma o desde especies hibridar, con las cuales, la planta cultivada se puede natural (Jacobsen \& Schouten, 2007), no es considerada un método de transformación genética en esta revisión, sino una de los formas de ingeniería genética de plantas. Ello, debido a que para desarrollar la cisgenesis se puede utilizar cualquiera de los métodos descritos.

\section{MÉTODOS INDIRECTOS}

Son métodos basados en la utilización de vectores biológicos, empleando sus característica naturales de patogenicidad en plantas, para la introducción de los genes de interés al genoma vegetal (Veluthambi et al. 2003; Rao et al. 2009). Entre estos sistemas de transformación se han descrito el uso de la bacteria Agrobacterium tumefaciens y el uso de virus. 


\section{Sistema Agrobacterium}

Debido a la capacidad y a la eficiencia de este género en infectar diversos organismos vegetales surgió la idea de utilizar Agrobacterium como mediador para la introducción de genes de interés en plantas (Hellens \& Mullineaux, 2000; Tzfira et al. 2004). La transformación mediada por Agrobacterium fue el primer sistema de transferencia de genes en producir una planta modificada genéticamente en 1983, cuando reportaron la transferencia de genes bacterianos a plantas y de una especie vegetal a otra (Valentine, 2003; Vasil, 2007).

La infección por Agrobacterium en una planta es el resultado de un proceso de evolución altamente especializado: la transferencia horizontal de genes desde bacterias hacia plantas (Gelvin, 2000; Zupan et al. 2000; Gelvin, 2003a; Tzfira \& Citovsky, 2002). El segmento de DNA transferido es conocido como la región T-DNA (DNA de transferencia) y se encuentra en el plásmido residente de la bacteria llamado plásmido $\mathrm{Ti}$ (inductor de tumores). Esta región contiene genes que codifican para la biosíntesis de fitohormonas y opinas (carbohidratos únicamente metabolizables por la bacteria). Para que se dé una transferencia efectiva de esta región es necesaria la expresión de los "genes Vir" contenidos en la región Vir (región de virulencia), la cual, se encuentra en el plásmido TI (Gelvin, 2000; Hellens \& Mullineaux, 2000; Gelvin, 2010).

Este proceso inicia cuando se producen heridas en las células de la planta, se liberan al medio compuestos fenólicos y monosacáridos, que son reconocidos por Agrobacterium, induciendo una unión entre la bacteria y las células vegetales. Este proceso de anclaje no ha sido dilucidado claramente (Citovsky et al. 2007; Escobar \& Dandekar, 2003; Karami et al. 2009). Los compuestos fenólicos, monosacáridos y condiciones de $\mathrm{pH}$ que presenta el medio circundante son importantes para la activación del sistema de regulación de dos componentes VirA/VirB, que activa la transcripción del regulon Vir (Valentine, 2003; Tzfira et al. 2004; Pitzschke \& Hirt, 2010). Posteriormente, por la acción cooperativa de las proteínas VirD1 y VirD2 permite la síntesis del T-DNA; la proteína VirD2 se une covalentemente al extremo 5' del T-DNA, mientras que la proteína VirE2 cubre a toda la hebra de T-DNA. Finalmente, este complejo es translocado a las células vegetales, mediante un sistema de secreción tipo IV, que está constituido por un Pili y un canal de secreción, formados por las proteínas VirB y VirD4. Una vez el T-DNA ha llegado a la célula vegetal, las proteínas VirE2 y VirD2 contribuyen al direccionamiento del T-DNA hacia el núcleo y posterior integración en el genoma vegetal (Tzfira \& Citosky, 2002; Tzfira et al. 2004; Citovsky et al. 2007; Escobar \& Dandekar, 2003). Cabe anotar que durante todo el proceso de infección de Agrobacterium, se da una continua interacción con las proteínas y sistemas propios de la célula vegetal a ser infectada (Gelvin, 2003b; Gelvin, 2010).

Para utilizar el sistema de transformación mediado por Agrobacterium, se requiere de cepas desarmadas, que son aquellas, en las que el T-DNA ha sido eliminado. Para obtenerlas, el plásmido residente $\mathrm{Ti}$ debe ser modificado mediante un proceso de recombinación, que permite eliminar los genes responsables de la formación de tumores en la planta, denominados ONC (oncogenes) y los genes OPS para la síntesis de opinas, que se encuentran en la región del T-DNA. Para esto es introducido a la cepa de Agrobacterium a desarmar, un plásmido foráneo con regiones de homología con el T-DNA y un gen para resistencia a antibióticos. Dado el proceso de recombinación entre el plásmido TI y el plásmido foráneo, se elimina el T-DNA y se introduce en el plásmido TI el gen para resistencia a antibióticos que, posteriormente, va permitir identificar la bacteria desarmada, mientras que plásmido foráneo con la región T-DNA es eliminado (Gelvin, 2003b; Jacobs, 2003; Gelvin, 2010; Pitzschke \& Hirt, 2010).

En la transferencia de genes, a través del sistema $A$. tumefaciens, se emplean dos tipos de vectores: los de cointegración (sistemas en cis) y los binarios. Los vectores co-integrados resultan de la integración de un plásmido foráneo pequeño al plásmido TI de la cepa desarmada de Agrobacterium, mediante un proceso de recombinación. Estos vectores, se obtienen a partir de un plásmido $\mathrm{Ti}$ desarmado, que contiene el borde izquierdo y el plásmido foráneo, que contiene el gen de interés flanqueado por el borde derecho y una región homóloga al borde izquierdo; la recombinación se lleva a cabo por un evento de entrecruzamiento de regiones homólogas de los dos plásmidos, dando como resultado un solo plásmido (Gelvin, 2000; Gelvin, 2003a; Gelvin, 2010).

Los vectores binarios (sistemas en trans) es la estrategia más empleada. Estos vectores, se derivan de plásmidos que se replican en $E$. coli y en $A$. tumefaciens, no necesitan integrarse al plásmido Ti y se mantienen como plásmidos independientes, dentro de la célula bacteriana. Esta estrategia consiste en el uso de dos plásmidos en la bacteria, uno de ellos, el vector binario, contiene los bordes del T-DNA en el que se incluye el casete de expresión o genes de interés y, el otro, el plásmido residente es el que contiene los genes "Vir", que son los encargados de mediar la transferencia efectiva del casette de expresión hacia las células vegetales (Hellens \& Mullineaux, 2000; Komori et al. 2007). Una versión mejorada de los vectores binarios son los vectores superbinarios, los cuales, son los responsables de la supervirulencia de las cepas de Agrobacterium, debido a que portan un segmento de DNA con los genes de virulencia VirB, VirC y VirG. Estos vectores, se obtienen a partir de la recombinación homóloga 
entre un plásmido pequeño que porta el T-DNA con los genes de interés y un plásmido de mayor tamaño que posee la región de supervirulencia, formando un vector co-integrado, que se introducirá a una cepa de Agrobacterium desarmada, como vector binario (Komori et al. 2007).

La transformación, mediada por Agrobacterium, requiere de un periodo de co-cultivo, en el cual, la cepa de Agrobacterium, que contiene el vector con los genes de interés, es puesta en contacto con el tejido vegetal a transformar, para que se realice la transferencia de T-DNA a algunas de las células vegetales expuestas a la infección. El uso de diferentes tipos de tejido vegetal está dado por las características de éstos, en cuanto a su capacidad de regeneración y fácil manipulación. El co-cultivo, se debe dar en un medio apropiado que favorezca el proceso de transformación, como la presencia de moléculas señal, como la acetosiringona y las heridas en el tejido vegetal que activa el sistema de virulencia de Agrobacterium (Vasil, 2007; Sharma et al. 2002; Hansen \& Wright, 1999).

Después del co-cultivo, el tejido vegetal es transferido a un medio de cultivo de tejidos vegetales que propicie la regeneración, que consiste en la obtención de una planta completa a partir de una célula vegetal. Para la regeneración de plantas completas es necesaria la adición de hormonas vegetales o reguladores de crecimiento al medio de cultivo. Estos reguladores son del tipo citoquininas, que promueven la división celular en el cultivo de tejidos no meristemáticos e inducen la formación de órganos en una gran variedad de cultivo de tejidos o auxinas, que promueven la división y crecimiento celular, y las giberilinas involucradas en la regulación de la elongación celular específicamente auxinas y citoquininas (Arias et al. 2006; Eapen, 2008; Pitzschke \& Hirt, 2010). El factor más importante para la regeneración es el balance adecuado de los reguladores de crecimiento. Entre los factores que pueden afectar de manera considerable la regeneración están la fuente del explante y su estado fisiológico, al igual que las condiciones de luz y de temperatura a que sean sometidos. Adicionalmente, estos medios deben contener antibióticos, que permita la eliminación de Agrobacterium, debido a que no es requerido más, puesto que el proceso de transformación se llevó a cabo en el periodo de co-cultivo y agentes selectivos, que permitan la selección de las posible plantas transgénicas, que debe estar de acuerdo con los genes de selección presentes en el casete de expresión empleado (Bhat \& Srinivasan, 2002; Filipecki \& Malepszy, 2006).

El sistema Agrobacterium es el más empleado en la producción de plantas transgénicas, debido a que posee varias ventajas frente a los otros sistemas de transformación. Entre estas están: simplicidad técnica de los protocolos; no requiere de equipos sofisticados; pueden ser empleados diferentes tipos de tejidos vegetales; la integración del T-DNA es un proceso relativamente preciso; la región de DNA a ser transferido es definida; baja probabilidad de rearreglos; permite la introducción de segmentos largos de DNA; bajo número de copias del T-DNA transferido. La gran mayoría de las ventajas que presenta este sistema, se explican por el proceso de infección de las células vegetales por la bacteria y la posterior integración del el T-DNA en el genoma vegetal (Hansen \& Wright, 1999; Veluthambi et al. 2003; Filipecki \& Malepszy, 2006).

Entre las desventajas del sistema de Agrobacterirum, se han reportado: el tejido a infectar debe presentar daño físico; los vectores están diseñado solo para infectar el núcleo; se requiere la eliminación de la bacteria de los tejidos infectados mediante el uso de antibiótico; el rango de hospederos está limitado a que estos sean susceptibles a la infección; sin embargo, muchas de estas deficiencias han sido superadas con la implementación de nuevas técnicas y procedimientos (Hansen \& Wright, 1999; Pitzschke \& Hirt, 2010).

Con el propósito de mejorar el sistema Agrobacterium, algunos investigadores proponen combinarlo con otras técnicas de transformación. Es así como surge la Agroinfiltración, que combina el sistema Agrobacterium con la aplicación de vacío. Se emplea tejido floral joven o en desarrollo, sobre el cual, se aplica vacío, mientras se encuentra sumergido en una solución concentrada de Agrobacterium. Esto permite que se produzcan heridas en el tejido, facilitando e incrementando la infección, además como se realiza en plantas ya desarrolladas, no es necesaria la utilización de cultivo de tejidos. Finalmente, lo que se logra es la infección del tejido floral femenino, partir del cual, se van a obtener semillas potencialmente transgénicas (Sharma et al. 2002; Grabowska \& Filipecki, 2004; Rao et al. 2009).

Otro método en el que se combina el sistema Agrobacterium con ultra sonido es llamado "transformación mediada por Agrobacterium asistida con sonicación" o SAAT, por sus siglas en idioma inglés. En este sistema, el tejido a transformar es sometido a periodos cortos de ultrasonido, ocasionándole pequeñas fisuras o heridas en el tejido vegetal, lo que facilita la infección por Agrobacterium (Beranova et al. 2008; Liu et al. 2006).

Un sistema de transformación basado en las característica propias del sistema Agrobacterium es el sistema TransBacter $^{\mathrm{TM}}$, que emplea otros géneros bacterianos, como Rhizobium sp., Sinorhizobium meliloti y Mesorhizobium loti, para transferir material genético a células vegetales. Estas bacterias, se pueden volver competentes para integrar genes en las plantas si se les introduce un plásmido Ti desarmado y un vector binario. Este sistema de transformación se 
encuentra disponible para la comunidad internacional de investigación y desarrollo, como una "tecnología común protegida", bajo una licencia BIOS, que es licencia para innovaciones en biotecnología basada en el concepto de código abierto (Broothaerts et al. 2005; BiOS, 2008).

\section{Vectores virales}

Algunos virus que afectan especies vegetales han sido empleados como vectores para la transformación de plantas, con el objetivo de producir proteínas de interés, por la expresión transitoria de genes foráneos, mediante la replicación de los virus en las plantas. Los virus deben ser modificados para que sean capaces de transportar el gen de interés al interior de la célula vegetal. Se han desarrolla dos estrategias para la construcción de vectores virales. En la más empleada, el gen foráneo, es introducido dentro del virus completo, por lo general, precedido por el promotor duplicado de la proteína de la capside del virus (promotor fuerte) o fusionado a ésta, para que el gen de interés sea expresado como un RNA subgenómico separado. La segunda estrategia y las más recientemente desarrollada, el virus es completamente reconstruido eliminando o sustituyendo regiones virales, además de la inserción del gen de interés. Finalmente, estos vectores virales pueden ser empleados en la transfección de la planta, como una partícula viral madura o como copias del vector viral (Gleba et al. 2004; Gleba et al. 2007).

Los mayores avances se han logrado con Geminivirus y Caulimovirus, debido a que estos son virus DNA y se pueden clonar directamente; dentro de estos ha sido especialmente utilizado el virus del mosaico de coliflor, con el cual, se ha logrado transferir genes con resistencia a antibióticos. También los virus RNA que son muy abundantes en el reino vegetal, se han empleado como vectores virales aunque estos debe ser clonados como cDNA, los más empleados son los del mosaico de la cebada y el virus del mosaico del tabaco (Sattar et al. 2006).

Entre las ventajas que presentan los vectores virales, se reportan: facilidad en la infección; rango de hospedadores más amplio; producción de altos niveles de proteína; los genes transmitidos no se limitan a una célula se esparcen por toda la planta; mayor velocidad en la expresión; sin embargo, existen varias limitaciones importantes: el tamaño del gen de interés debe ser limitado para que no afecte la infectividad; pueden provocar síntomas específicos de enfermedad o ser letales para la planta huésped; alta frecuencia de errores durante la síntesis del ARN vírica puede dar lugar a la expresión incorrecta del gen introducido; el gen de interés no se integra en el genoma vegetal y no se transfiere necesariamente a la descendencia (Sattar et al. 2006; Gleba et al. 2004). Es importante anotar que la mayor y principal aplicación de este sistema está en la producción de proteínas heterólogas, como biofármacos (Sattar et al. 2006).

Otro sistema de transformación que ha surgido a partir de la combinación de las características de los vectores víricos y del sistema Agrobacterium es la Agroinfección. En esta metodología, se emplea el sistema de transferencia del DNA de Agrobacterium para infectar células vegetales con vectores virales. El vector viral es introducido en el T-DNA, el cual, es transferido a las células por el proceso normal de infección, mediada por Agrobacterium. Este sistema es empleado cuando los vectores virales provienen de virus que no son transmisibles mecánicamente (Larik et al. 2004; De Oliveira et al. 2008).

\section{MÉTODOS DIRECTOS}

Debido a la dificultad de transformar monotiledóneas por medio de Agrobacterium, se desarrollan sistemas de transferencia de genes, en los que se emplea procedimientos de naturaleza química, fisicoquímica y mecánica. El desarrollo de estos métodos, se basó en las técnicas físicas usadas en la transformación de células animales en cultivo (Díaz et al. 2004; Gutiérrez et al. 2002; Danilova, 2007; Rao et al. 2009).

\section{Liposomas}

Los liposomas o vesículas lipídicas están conformadas por varias bicapas de lípidos que encapsulan agua o gas, poseen diámetros del orden de nanómetros, con diferentes formas y tamaños. Pueden estar formados por fosfolípidos, fosfatidiletanolamina, ácidos grasos o cationes bivalentes. Los liposomas presentan característica muy similares a las membranas biológicas, con una tendencia natural a ligarse a células y tejidos interactuando con estos por absorción, fusión o intercambio lipídico. (Morigaki \& Walde, 2007; Hotani et al. 2003).

Entre los métodos para transformación vegetal, la transferencia de genes, mediada por liposomas, es uno de los más difíciles y aunque en un principio éste mostró ser eficaz, su utilización ha sido muy limitada. En este método, el casete de expresión es encapsulado en una esfera lipídica (liposoma), que permite o facilita su paso, a través de la célula vegetal por endocitosis, ya sea por el plasmodesma o directamente por la pared celular, hasta el núcleo (Rao et al. 2009).

Los métodos de transferencia mediados por liposomas poseen algunas ventajas, como son: protección contra la degradación por nucleasas; capacidad de portar grandes fragmentos de DNA; biocompatibilidad con membranas; no requiere de un portador para el DNA. Los problemas que 
se han reportado con este sistema de transformación, son: frecuencia de transformación muy baja; inserción del DNA en tandem; preparación de los liposomas; encapsulación del material genético a transferir. Estos problemas se han solucionado parcialmente con la implementación de nuevas técnicas y la utilización de nuevos compuestos, para la preparación de liposomas (Vasil, 2007).

Pese a las dificultades que presenta este sistema, la fusión de liposomas que contienen ADN con protoplastos está bien establecida en la producción de plantas transgénicas. Menos exitosa ha sido la fusión de los liposomas con tejidos y células vegetales intactas. La eficacia del método aumenta al combinarlo con otras técnicas, como el tratamiento con PEG (Polietilenglicol) o la electroporación (Mok \& Park, 2008).

\section{Biobalística}

El término biobalística proviene de la unión de "biología y balística". Este método fue ideado y refinado en la década de 1980, por un grupo de investigadores de la Universidad de Cornell (E.U.) e introducido por Sanford, en 1987, por primera vez. Esta técnica, se basa en la utilización de microproyectiles recubiertos del DNA que se desea transferir, que son disparados sobre los tejidos vegetales a altas velocidades, atraviesan la pared y la membrana celular y llevan al interior de la célula los genes de interés para su posterior integración en el genoma vegetal (Sanford, 2000; Martínez et al. 2004; Vasil, 2007).

Este sistema de transformación requiere de un dispositivo mecánico que permita realizar el bombardeo de los tejidos vegetales. Para que los microproyectiles puedan atravesar las membranas celulares y llegar al núcleo de las células blanco, deben ser impulsados a velocidades supersónicas. Para ello, se desarrollaron tres sistemas: por explosión de pólvora seca, por variación de fuerza de aceleración, a través de descarga eléctrica o por liberación de gas comprimido a alta presión (aire, helio, CO2 o N2). Los microproyectiles empleados son partículas aproximadamente esféricas (microesferas), elaboradas de materiales densos, como el oro o tungsteno, de diámetro variados, que pueden ir desde los $0,4 \mu \mathrm{m}$ hasta $4 \mu \mathrm{m}$. El casete de expresión con los genes de interés puede ir o no en un vector, ya que no es requerido para el proceso de transformación. El casete de expresión debe ser adherido a los microproyectiles y, para esto, se han diseñado varias metodologías, entre las más utilizada es la que emplea cloruro de calcio y espermidina, para la precipitación del DNA sobre los micorproyectiles (Bhat \& Srinivasan, 2002; Altpeter et al. 2005; Sanford, 2000; Rao et al. 2009).

En la actualidad, el mecanismo de disparo se basa en una pistola especial que lanza las partículas a más de $400 \mathrm{~m} / \mathrm{s}$ sobre el tejido de forma, que penetran sin destruir la membrana celular. Todo el sistema funciona en un vacío moderado para evitar el rozamiento con el aire, condiciones que las células vegetales soportan durante uno o dos minutos. Tras el bombardeo, el DNA se desprende de los microproyectiles, debido a las modificaciones del entorno iónico. De acuerdo con la localización de los microproyectiles en la célula, el DNA se puede integrar de forma estable en núcleo, cloroplastos o mitocondrias de las células vegetales, mediante recombinación al azar. Finalmente, los tejidos son colocados en condiciones adecuadas para la regeneración de plantas, mediante técnicas de cultivo de tejidos vegetales. Cabe anotar que los tejidos vegetales empleados son sometidos a un tratamiento osmótico pre y pos bombardeo, con el fin de evitar el daño de las células por el procedimiento (Taylor \& Fauquet, 2002; Altpeter et al. 2005; Sanford, 2000; Rao et al. 2009).

El bombardeo de micropartículas es considerado un mecanismo universal por su naturaleza física, que permite introducir DNA sin necesidad de vectores especializados, en cualquier tipo de tejido o célula, alcanzando capas profundas. Con un disparo, se pueden producir múltiples integraciones. En este método de transformación, las construcciones genéticas son más simples, incluyen los genes de interés y de selección con sus secuencias reguladoras respectivas, pueden ir incluidas en plásmidos o en forma de molécula lineal (Altpeter et al. 2005; Sanford, 2000; Taylor \& Fauquet, 2002).

Esta técnica fue propuesta, inicialmente, para introducir material genético en el genoma nuclear de plantas superiores, pero en los últimos años se ha usado para transformar bacterias, protozoos, hongos, algas, insectos, tejidos animales y plantas in vivo. Además, en la actualidad, constituye el único método de transformación, que permite transformar organelos celulares (Mohan Babua et al. 2003; Larik et al. 2004).

Entre las desventajas que presenta este sistema, se encuentran: porcentaje de éxito variable; es frecuente la inserción de varias copias del casete de expresión variando desde 1 hasta 20, que pueden ir en tandem, causando silenciamiento génico; muchas veces no se consigue una introducción estable del transgen; se presentan rearreglos en el DNA transferido que difieren en tamaño; se puede presentar daño en los tejidos; el sistema es cotoso (Hansen \& Wright, 1999; Veluthambi et al. 2003; Danilova, 2007).

Un sistema de transformación que ha surgido a partir de integrar las características de este sistema con el sistema Agrobacterium es la Biolistica o Agrolistica. En éste, se emplea la biobalística para producir daños mecánicos al disparar proyectiles sin ADN sobre el tejido vegetal a 
transformar, luego, a través del sistema Agrobacteriumk, como mecanismo de transmisión génica, se lleva a cabo la transformación del tejido vegetal. (Taylor \& Fauquet, 2002; Sharma et al. 2002).

\section{Electroporación}

Con esta metodología, se busca permeabilizar las membranas, mediante el aumento significativo de la conductividad eléctrica, causado por un campo eléctrico aplicado externamente. Las membranas, se desestabilizan originando una pérdida temporal de la permeabilidad produciendo poros reversibles, por los que se produce el paso de macromoléculas, fuga de iones, escape de metabolitos y mayor absorción de DNA, por parte de las células (Krassowska \& Filev, 2007; Fox et al. 2006).

Durante la electroporación, las células son tratadas con impulsos eléctricos controlados de alto voltaje y pulsos cortos de duración de microsegundos a milisegundos, utilizando campos entre los $200 \mathrm{~V} / \mathrm{cm}$ hasta los $600 \mathrm{~V} / \mathrm{cm}$. Cuando el voltaje que atraviesa una membrana plasmática excede su rigidez dieléctrica, siendo esta la resistencia que oponen los materiales a transmitir la electricidad, se forman poros en la membrana. Si la fuerza del campo eléctrico aplicado y la duración de la exposición al mismo se eligen correctamente, los poros formados por el pulso eléctrico se sellan tras un corto periodo de tiempo, durante, el cual, los compuestos extracelulares tienen la oportunidad de entrar a la célula; sin embargo, una exposición excesiva a campos eléctricos puede causar daños irreversibles a las membranas, causando la muerte de las células (Tarek, 2005; Chen et al. 2006).

La electroporación se lleva a cabo en un dispositivo llamado electroporador, aparato que utiliza descargas de capacitores para producir pulsos de alto voltaje, originando una corriente eléctrica, que se hace pasar a través de la suspensión, que contiene las células, a las cuales, se les desea permeabilizar sus membranas y así permitir o facilitar la entrada del DNA foráneo, con el que se pretende transformar las células. El DNA foráneo a introducir debe estar presente en la solución con las células a transformar; este DNA o genes de inertes, por lo general, se encuentran contenidos en un plásmido, aunque también pueden estar en forma de molécula lineal de DNA (Fox et al. 2006; Chen et al. 2006).

El proceso de electroporación es aproximadamente diez veces más efectivo que la transformación mediada por métodos químicos; es un método muy eficiente de fácil operación y relativamente simple, que se utiliza con mucha frecuencia. La principal limitación que presenta este método para la transformación de plantas es la necesidad de emplear protoplastos (células sin pared), para que se pueda llevar a cabo la permeabilización de la membrana plasmática. El empleo de protoplastos conlleva a la implementación de técnicas de cultivo engorrosas (Mohan Babua et al. 2003; Larik et al. 2004).

\section{Sonicación}

Es un método nuevo de transferencia de genes, utilizado con éxito en la transformación de tejidos vegetales, células intactas y protoplastos. Se emplea ultrasonido con frecuencias superiores a $20 \mathrm{KHz}$, para generar permeabilidad en las membranas, mediante la inducción de poros transitorios, a través de los cuales, el DNA foráneo puede ingresar al interior de la célula vegetal. Este fenómeno también es conocido como Sonoporación. El dispositivo empleado para la producción de los pulsos de ultrasonido empleados durante este proceso es conocido como sonicador (MehierHumberta et al. 2005; Deng et al. 2004)

El mecanismo por el que se ocasiona la permeabilización de las membranas por la acción de ultrasonido no se dilucidado por completo. Se cree que el mayor efecto de la sonicación es debido a la cavitación acústica, siendo esta la propagación de las hondas del ultrasonido, por medio de un medio líquido en reposo, particularmente a bajas energías acústicas. Por causa a este fenómeno, se producen burbujas que crecen, con rápidas oscilaciones en su tamaño, lo que las hace colapsar. Durante este colapso, las burbujas producen ondas de choque muy fuertes, así como pequeños chorros de líquido a altas velocidades, produciendo daños severos en la superficie de objetos sólidos cercanos (MehierHumberta et al. 2005; Miller et al. 2002).

Los efectos fisicoquímicos que este proceso puede ocasionar a las células vegetales son: formación de radicales libres; daños en la pared celular; alteraciones en la permeabilidad de la membrana; aberraciones cromosómicas menores; cambios de tipo fisiológico. Dado que se ha logrado mediante este procedimiento la introducción de manera eficiente de ADN foráneo y del hecho que se pueden utilizar protoplastos, células en suspensión y fragmentos de tejido, es factible que esta técnica pueda tener un potencial futuro (Liu et al. 2006; Deng et al. 2004).

\section{Transferencia mediada por compuestos químicos}

Es una de las metodologías más empleada para la introducción de DNA foráneo en protoplastos y en células intactas. Se basa en el uso de compuestos químicos que induzcan permeabilidad en la membrana. Para esto, las células vegetales deben ser tratadas con la sustancia química en las concentraciones y en las condiciones pre-establecidas. Entre los compuestos químicos más empleados tenemos: Polietilenglicol (PEG), Fotostato de calcio y Poly-L-omotina. Estas sustancias ayudan a inducir permeabilidad en las membra- 
nas, mediante la inducción de poros transitorios o daño reversible de la membrana, lo que permite o favorece el paso del DNA foráneo y de macromoléculas, a través de la membrana hacia el interior de la célula. Esta fue la primera técnica alternativa que se empleó para transformar gramíneas, en la década de los 80 (Chakrabarty et al. 2008; Danilova, 2007).

El más empleado de los compuestos químicos es el Polietilenglicol (PEG), un agente de fusión que modifica químicamente las membranas al interaccionar con los fosfolípidos que las componen. Durante el tratamiento con PEG, la membrana de la célula es deformada por fuerzas de tensión superficial, causadas por las diferencias de densidades entre la solución de PEG y la solución que contiene los protoplastos a transformar y el DNA foráneo que se desea introducir. Es común que se emplee un $\mathrm{pH}$ alcalino, que contribuye al daño en la membrana; también se adicionan iones de calcio, que facilitan la entrada del DNA foráneo al interior de la célula. Pese a que este sistema presenta algunas desventajas, como baja eficiencia, poca reproducibilidad, requerimiento de protoplastos y toxicidad para las células, se continúa empleando intensivamente (Danilova, 2007).

\section{Fibras de carburo de silicona}

Es una metodología recientemente descrita, en la que se emplean fibras de carburo de silicona de 10 a $80 \mu \mathrm{m}$ de longitud, con un diámetro de 0,5 $\mu \mathrm{m}$, mediante, la cual, el DNA foráneo es introducido en las células vegetales, a través de los poros o agujeros que hacen las fibras de carburo de silicona, que actúan como microagujas. El tamaño, la forma y la composición química de las fibras de carburo de silicona es lo que permite que penetren directamente al interior de la célula, sin ocasionarle daño alguno (Danilova, 2007; Lutsenko, 2005).

La metodología por la que se realiza el proceso de transformación empleando las fibras de carburo de silicona es bastante sencilla; mediante una fuerte agitación del cultivo celular en suspensión, en presencia del DNA plasmídico y las fibras de carburo de silicona, se logra que por fuerzas hidrodinámicas penetre a las células el DNA foráneo y las fibras de carburo de silicona. Esta técnica es rápida, sencilla y poco costosa. Aunque es necesario aclarar los mecanismos moleculares que actúan en estas transformaciones, así como ensayar nuevos materiales fibrosos que mejoren los resultados obtenidos y permitan eliminar el uso del material carburo de silicona que es toxico (Mizuno et al. 2005; Rao et al. 2009).

\section{Microinyección}

La microinyección es una de las técnicas más precisas para la introducción de DNA foráneo o de macromoléculas dentro de los compartimentos intracelulares específicos de las células. La microinyección utiliza microcapilares o microagujas de vidrio y sistemas de microscopia para depositar el DNA foráneo, en el interior de células vegetales. Además, el hecho que junto al DNA desnudo se puedan inyectar otros elementos genéticos, como plastidios, mitocondrias y cromosomas, hace de la microinyección una técnica interesante y muy útil para la transformación de plantas. El equipo que se requiere para realizar el proceso de microinyección es llamado micro manipulador, compuesto por un microscopio y por los accesorios de guía, para realiza desplazamientos (Sharma et al. 2002; Holm et al. 2000).

Entre las ventajas que presenta esta técnica, se han reportado: se puede optimizar la cantidad de DNA descargado; se puede escoger la célula a transformar; la descarga del DNA foráneo es precisa y predecible; el proceso se realiza bajo control visual; se emplean cantidades micro. Pero también presenta algunas desventajas, tales como: solamente una célula recibe el DNA por cada inyección; el manejo de la técnica requiere personal entrenado y mayor instrumentación (Mohan Babua et al. 2003; Larik et al. 2004).

Uno de los grandes avances que se han logrado con este método ha sido la implementación de microinyección de liposomas, en los que se ha depositado el DNA de interés, facilitando así la descarga o introducción del DNA foráneo en la célula (Gutiérrez et al. 2002; Larik et al. 2004; Rao et al. 2009).

\section{Microláser}

El objetivo de esta metodología es la permeabilización de las membranas, que se lleva a cabo mediante la utilización de un chorro de microláser enfocado en el sistema de iluminación de un microscopio, permitiendo así abrir orificios o poros transitorios en la pared celular y en la membrana plasmática de las células vegetales, que se desean transformar. Así, se facilita la posterior entrada del DNA foráneo hacia el interior de las células. Como en este sistema no requiere de vectores o portadores del DNA de interés, para el proceso de transformación, se pueden emplear moléculas de DNA lineales (Kajiyama et al. 2007; Mohan Babua et al. 2003).

No hay datos concluyentes acerca de la eficacia de este método. Pero en combinación con el sistema de biobalística, se han obtenido logros importantes en procesos de transformación. Así se emplea este método para abrir poros en los tejidos vegetales, para que posteriormente los microproyectiles cargados con el DNA foráneo, penetre las células vegetales (Kajiyama et al. 2007; Mohan Babua et al. 2003).

\section{CONCLUSIONES}

Existe un gran número de métodos de transformación de plantas que se encuentran disponibles para su uso, aunque 
la mayoría son muy poco utilizados en el laboratorio. Los métodos más empleados son la transformación mediada por Agrobacterium y la Biobalística, tanto para usos experimentales como para usos comerciales. Algunos de nuevos métodos pueden cobrar interés, ya que son más sencillos, contribuyen a la reducción de costos y a una demanda más baja, en el uso de equipos. Aunque para muchos de estos métodos se deben realizar ensayos y estudios para su optimización, empleando diferentes genotipos, puesto que la mayoría presenta un gran problema, que es la baja eficiencia de transformación. La eficiencia de estos sistemas está supeditada a los métodos de cultivo de tejido que se empleen y a los avances que en esta área se tenga sobre el genotipo a transformar.

Conflictos de intereses: El manuscrito fue preparado y revisado con la participación de todos los autores, quienes declaran que no existe ningún conflicto de intereses que ponga en riesgo la validez de los resultados presentados.

\section{BIBLIOGRAFÍA}

1. AGROBIO, 2011. Estadísticas de cultivos GM (2010). (Colombia) Disponible desde Internet en http://agrobio.org.co/fend/index. php?op $=$ YXA9I2JXbDQmaW09I016UT0 $=\quad($ con acceso 08/10/2011).

2. ALTPETER, F.; BAISAKH, N.; BEACHY, R.; BOCK, R.; CAPELL, T.; CHRISTOU, P.; DANIELL, H.; DATTA, K.; DATTA, S.; PHILIP, J.; DIX, P.; FAUQUE, C.; HUANG, N.; KOHLI, A.; MOOIBROEK, H.; NICHOLSON, L.; NGUYEN, T.; NUGENT, G.; RAEMAKERS, K.; ROMANO, A.; SOMERS, D.; STOGER, E.; TAYLOR, N.; VISSER, R. 2005. Particle bombardment and the genetic enhancement of crops: myths and realities. Molec. Breeding. (Holanda). 15:305-327.

3. ARIAS, R.; FILICHKIN, S.; STRAUSS, S. 2006. Divide and conquer: development and cell cycle genes in plant transformation. Trends Biotechn. (Holanda). 24(6):267-273.

4. BHAT, R.; SRINIVASAN, S. 2002. Molecular and genetic analyses of transgenic plants: Considerations and approaches. Plant Sci. (Holanda). 163:673-681.

5. BERANOVA, M.; RAKOUSKY, S.; VAVROVA, Z.; SKALICKY, T. 2008. Sonication assisted Agrobacterium-mediated transformation enhances the transformation efficiency in flax (Linum usitatissimum L.). Plant Cell Tiss. Organ. Cult. (Holanda). 94(3):253-259.
6. BIOS. 2008. BiOS: a framework to collaboratively solve our shared challenges. CAMBIA (Australia). Disponible desde Internet en http://www.bios.net./ daisy/bios/home.html (con acceso 08/10/2011).

7. BIRCH, R. 1997. Plant transformation: Problems and Strategies for Practical Application. An. Rev. Plant Physiol. Plant Mol. Biol. (Estados Unidos). 48:297326.

8. BROOTHAERTS, W.; MITCHELL, H.; WEIR, B.; KAINES, S.; SMITH, L.; YANG, W.; MAYER, J.; ROARODRIGUEZ, C.; JEFFERSON, R. 2005. Gene transfer to plants by diverse species of bacteria. Nature (Inglaterra). 433:629-633.

9. CITOVSKY, V.; KOZLOVSKY, S.; LACROIX, B.; ZALTSMAN, A.; DAFNY-YELIN, M.; VYAS, S.; TOVKACH, A.; TZFIRA, T. 2007. Biological systems of the host cell involved in Agrobacterium infection. Cell. Microbiol. (Alemania). 9(1):9-20.

10. CHAKRABARTY, B.; GHOSHAL, A.; PURKAIT, M. 2008. Effect of molecular weight of PEG on membrane morphology and transport properties. J. Membr. Sci. (Holanda). 309:209-221.

11. CHAPARRO, A.; CANCINO, G.; CARVAJAL, D.; DIAZGRANADOS, C.; MORENO, L.; NEMOGA, G.; RAMÍREZ, H.; SILVA, C.; YAYA, M. 2005. Introducción a la ingeniería genética de plantas. Universidad Nacional de Colombia, Unibiblos. Bogotá, Colombia. 150p.

12. CHEN, C.; SMYE, S.; ROBINSON, M., EVANS J. 2006. Membrane electroporation theories: a review. Med. Biol. Eng. Comput. (Holanda). 44:5-14.

13. DANILOVA, S. 2007. The technologies for genetic transformation of Cereals. Russian J. Plant Physiol. 54(5):569-581.

14. DE OLIVEIRA, P.; OLIVEIRA, T.; NAGATA, T.; KAZUKO, A. 2008. One-step cloning approach for construction of agroinfectious begomovirus clones. J. Virol. Methods (Holanda). 147:351-354.

15. DENG, CH.; SIELING, F.; PAN, H.; CUI, J. 2004. Ultrasound-Induced Cell Membrane Porosity. Ultrasound Med. \& Biol. (Holanda). 30(4):519-526.

16. DÍAZ, M.; ZAPPACOSTA, D.; FRANZONE, P.; RÍOS, R. 2004. Transformación genética, Parte III, Capítulo 
3. En: ArgenBio (Consejo Argentino para la información y el desarrollo de la Biotecnología) eds. Biotecnología y mejoramiento vegetal. Ediciones INTA. Buenos Aires, Argentina. Disponible desde Internet en: www.argenbio.org/h/biblioteca/libro.php (con acceso 08/10/2011).

17. EAPEN, S. 2008. Advances in development of transgenic pulse crops. Biotechn. Adv. (Holanda). 26:162168.

18. ESCOBAR, M.; DANDEKAR, A. 2003. Agrobacterium tumefaciens as an agent of disease. Trends in Plant Sci. (Holanda). 8(8):380-386.

19. FILIPECKI, M.; MALEPSZY, S. 2006. Unintended consequences of plant transformation: a molecular insight. J. Appl. Genet. (Polonia) 47(4):277-286.

20. FOX, M.; ESVELD, D.; VALERO, A.; LUTTGE, R.; MASTWIJK, H.; BARTELS, P.; VAN DEN BERG, A.; BOOM, R. 2006. Electroporation of cells in microfluidic devices: a review. Anal Bioanal Chem. (Alemania). 385: 474-485.

21. GELVIN, S. 2000. Agrobacterium and plant genes involved in T-DNA transfer and Integration. An. Rev. Plant Physiol. Plant Mol. Biol. (Estados Unidos). 51:223-256.

22. GELVIN, S. 2003a. Agrobacterium-Mediated Plant Transformation: the Biology behind the "GeneJockeying" Tool. Microbiol. Molec. Biol. Rev. (Estados Unidos). 67(1):16-37.

23. GELVIN, S. 2003b. Improving plant genetic engineering by manipulating the host. Trends Biotechn. 21(3):9598.

24. GELVIN, S. 2010. Plant Proteins Involved in Agrobacterium-Mediated Genetic Transformation. An. Rev. Phytopathol. (Estados Unidos). 48:45-68.

25. GLEBA, Y.; MARILLONNET, S.; KLIMYUK, V. 2004. Engineering viral expression vectors for plants: the 'full virus' and the 'deconstructed virus' strategies. Curr. Opinion Plant. (Holanda). 7:182-188.

26. GLEBA, Y.; KLIMYUK, V.; MARILLONNET S. 2007. Viral vectors for the expression of proteins in plants. Curr. Opinion Biotechn. (Holanda). 18:134-141.

27. GRABOWSKA, A.; FILIPECKI, M. 2004. Infiltration with Agrobacterium - the method for stable transformation avoiding tissue culture. Acta Physiolog. Plant. (Holanda). 26(4):451-458.

28. GUTIÉRREZ, A.; SANTACRUZ, F.; CABRERA, J.; RODRÍGUEZ, B. 2002. Mejoramiento genético vegetal in vitro. e-Gnosis Revista digital: Ciencia y Tecnología (Méjico) 1: Art 4. Disponible desde Internet en: www.e-gnosis.udg.mx (con acceso 08/10/2011).

29. HANSEN, G.; WRIGHT, M. 1999. Recent advances in the transformation of plants. Trends Plant Sci. Rev. (Estados Unidos). 4(6):226-231.

30. HELLENS, R.; MULLINEAUX, P. 2000. A guide to Agrobacterium binary Ti vectors. Trends Plant Sci. Rev. 5(10):446-451.

31. HOLM, P.; OLSEN, O.; SCHNORF, M.; BRINCHPEDERSEN, H.; KNUDSEN, S. 2000. Transformation of barley by microinjection into isolated zygote protoplasts. Transgenic Res. (Holanda). 9:21-32.

32. HOTANI, H.; INABA, T.; NOMURA, F.; TAKEDA, S.; TAKIGUCHI, K.; ITOH, T.J.; UMEDA, T.; ISHIJIMA, A. 2003. Mechanical analyses of morphological and topological transformation of liposomes. BioSystems (Holanda). 71:93-100.

33. JACOBSEN, E.; SCHOUTEN, H. 2007. Cisgenesis strongly improves introgression breeding and induced translocation breeding of plants. Trends Biotechn. 25:219-223.

34. JACOBS, M. 2003. Developing the Agrobacterium Ti plasmidas a vector for plant genetic engineering: the 2002 Benjamin Franklin Medal in life sciences presented to Mary-Dell Chilton. J. Franklin Institute (Estados Unidos). 340:213-219.

35. JAMES, C. 2005. Global Status of Commercialized Biotech/GM Crops: 2005. ISAAA Brief No. 34. ISAAA: Ithaca, NY. p.30.

36. JAMES, C. 2008. Global Status of Commercialized Biotech/GM Crops: 2007. ISAAA Brief No. 37. ISAAA: Ithaca, NY. p.30.

37. JAMES, C. 2010. Global Status of Commercialized Biotech/GM Crops: 2009. ISAAA Brief No. 42. ISAAA: Ithaca, NY. p.30.

38. JAUHAR, P. 2006. Modern biotechnology as an integral 
supplement to conventional plant breeding: the prospects and challenges. Crop Sci. (Estados Unidos). 46:1841-1859.

39. JOB, D. 2002. Plant biotechnology in agriculture. Biochimie (Holanda). 84:1105-1110.

40. KAJIYAMA, S.; INOUE, F.; YOSHIKAWA, Y.; SHOJI, T.; FUKUSAKI, E.; KOBAYASHI, A. 2007. Novel plant transformation system by gene-coated gold particle introduction into specific cell using $\mathrm{ArF}$ excimer laser. Plant Biotechn. (Japón). 24:315-320.

41. KARIMI, M.; BLEYS, A.; VANDERHAEGHEN, R.; WILSON, P. 2007. Building blocks for plant gene assembly. Plant Physiol. (Estados Unidos). 145:11831191.

42. KARAMI, O.; ESNA-ASHARI, M.; KARIMI, G.; AGHAVAISI, B. 2009. Agrobacterium-mediated genetic transformation of plants: the role of host. Biol. Plant. (República Checa). 53(2):201-212.

43. KOMORI, T.; IMAYAMA, T.; KATO, N.; ISHIDA, Y.; UEKI, J.; KOMARI, T. 2007. Current status of binary vectors and superbinary vectors. Plant Physiol.145:1155-1160.

44. KRASSOWSKA, W.; FILEV, P. 2007. Modeling electroporation in a single cell. Biophys. J. (Estados Unidos). 92:404-417.

45. LARIK, A.; AHMED SIDDIQUI, K.; AHMED SOOMRO, Z. 2004. Novel vistas of gene transfer to cereals. Proc. Pakistan Acad. Sci. 41(2):153-164.

46. LIVERMORE, M. 2002. The role of modern biotechnology in developing country agriculture. Brit. Nutr. Found. Nutr. Bull. 27:47-50.

47. LIU, Y.; YANG, H.; SAKANISHI, A. 2006.Ultrasound: Mechanical gene transfer into plant cells by sonoporation. Biot. Adv. 24:1-16.

48. LUTSENKO, V. 2005. Nanostructural materials filamentary and tubular silicon carbide nanocrystals. Powder Metal. Metal Ceram. (Holanda). 44:1-2.

49. MARTÍNEZ, M.; CABRERA, J.; HERRERA, L. 2004. Las plantas transgénicas: una visión integral. e-Gnosis Revista digital. Ciencia y Tecnología (Méjico). 2: Art 2. Disponible desde Internet en: www.e-gnosis.udg. $\mathrm{mx}$ (con acceso 08/10/2011).
50. MEHIER-HUMBERTA, S.; BETTINGERB, T.; YANB, F.; GU, R. 2005. Ultrasound-mediated gene delivery: Kinetics of plasmid internalization and gene expression. J. Controlled Release. (Holanda). 104:203-211.

51. MILLER, D.; PISLARU, S.; GREENLEAF, J. 2002. Sonoporation: Mechanical DNA delivery by ultrasonic cavitation. Somatic Cell Mol. Genetics (Holanda). 27(1/6):115-134.

52. MIZUNO, K.; TAKAHASHI, W.; BEPPU, T.; SHIMADA, T.; TANAKA, O. 2005. Aluminum borate whiskermediated production of transgenic tobacco plants. Plant Cell, Tissue Organ Cult. (Holanda). 80:163169.

53. MOHAN BABUA, R.; SAJEENAB, A.; SEETHARAMANB, K. 2003. Advances in genetically engineered (transgenic) plants in pest management an over view. Crop Prot. (Holanda). 22:1071-1086.

54. MOK, H.; PARK T. 2008. Direct plasmid DNA encapsulation within PLGA nanospheres by single oil-in-water emulsion method. Eur. J. Pharmac. Biopharmac. (Holanda). 68:105-111.

55. MORIGAKI, K.; WALDE, P. 2007. Fatty acid vesicles. Curr. Opinion Colloid \& Interf. Sci. (Holanda).12:75-80.

56. NIELSEN, CH.; ROBINSON, S.; TIERFELDER, K. 2001. Genetic engineering and trade: Panacea or dilemma for developing countries. World Developm. (Holanda). 29 (8):1307-1304.

57. PITZSCHKE, A.; HIRT, H. 2010. New insights into an old story: Agrobacterium induced tumour formation in plants by plant transformation. The EMBO J. (Inglaterra). 29:1021-1032.

58. RAO, A.; BAKHSH, A.; KIANI, S.; SHAHZAD, K.; SHAHID, A.; HUSNAIN, T.; RIAZUDDIN, S. 2009. The myth of plant transformation. Biotechn. Adv. 27:753-763.

59. ROMMENS, C. 2004. All-native DNA transformation: a new approach to plant genetic engineering. Trends Plant Sci. 9(9):457-464.

60. SHARMA, K.; SHARMA, H.; SEETHARAMA, N.; ORTIZ, R. 2002. Development and deployment of transgenic plants: biosafety considerations. In Vitro Cell. Dev. Biol. Plant. (Holanda). 38:106-115. 
61. SANFORD, J. 2000. The development of the biolistic process. In Vitro Cell. Dev. Biol. Plant. 36:303-308.

62. SATTAR SANTI, L.; HUANG, Z.; MASON, H. 2006. Viruslike particles production in green plants. Methods (Holanda). 40:66-76.

63. TAREK, M. 2005. Membrane electroporation: a molecular dynamics simulation. Biophys. J. (Estados Unidos). 88:4045-4053.

64. TAYLOR, N.; FAUQUET, C. 2002. Microparticle bombardment as a tool in plant science and agricultural biotechnology. DNA and Cell Biology. (Estados Unidos). 21(12):963-977.

65. TZFIRA, T.; CITOVSKY, V. 2002. Partners-in-infection: host proteins involved in the transformation of plant cells by Agrobacterium. Trends Cell Biol. (Estados Unidos). 12(3):121-129.

66. TZFIRA, T.; LI, J.; LACROIX, B.; CITOVSKY, V. 2004. Agrobacterium T-DNA integration: molecules and models. Trends Genetics. (Estados Unidos). 20(8):375-383.
67. VAIN, P. 2007. Thirty years of plant transformation technology development. Plant Biotechn. J. (Estados Unidos). 5:221-229.

68. VASIL, I. 2007. A short history of plant biotechnology. Phytochem. Rev. (Holanda). 7:387-394.

69. VALENTINE, L. 2003. Agrobacterium tumefaciens and the Plant: The David and Goliath of Modern Genetics. Plant Physiol. 33: 948-955.

70. VELUTHAMBI, K.; GUPTA, A.; SHARMA, A. 2003. The current status of plant transformation Technologies. Current Sci. (India). 84:368-380.

71. ZUPAN, J.; MUTH, T.; DRAPER, O.; ZAMBRYSKI, P. 2000.The transfer of DNA from Agrobacterium tumefaciens into plants: a feast of fundamental insights. The Plant J. 23(1):11-28.

Recibido: Septiembre 8 de 2011

Aceptado: Abril 13 de 2012 